\title{
Erratum to: Controlling the response to DNA damage by the APC/C-Cdh1
}

\author{
H. Rudolf de Boer ${ }^{1} \cdot$ Sergi Guerrero Llobet ${ }^{1} \cdot$ Marcel A. T. M. van Vugt ${ }^{1}$
}

Published online: 1 June 2016

(C) Springer International Publishing 2016

\section{Erratum to: Cell. Mol. Life Sci. (2016) 73:949-960 DOI 10.1007/s00018-015-2096-7}

The references starting from 82 to 142 were missing in the original published article. The complete article with all the references is re-published here.

\section{Introduction}

Reproduction depends on successful cell division, which is coordinated in the cell cycle. Especially in the context of multicellular organisms, proper control of cell cycle initiation and completion is essential for successful development and homeostasis. Research in the past decades has revealed how cell cycle progression is coordinated by various pathways, which show extensive feedback loops and display multiple levels of cross-talk. Despite this complexity, the core of the cell cycle machinery is constituted by a highly evolutionary conserved molecular

H. R. de Boer and S. G. Llobet contributed equally to this work.

The online version of the original article can be found under doi:10.1007/s00018-015-2096-7.

Marcel A. T. M. van Vugt

m.vugt@umcg.nl

1 Department of Medical Oncology, Cancer Research Center Groningen, University Medical Center Groningen, University of Groningen, Groningen, The Netherlands 'engine', called the cyclin/cyclin-dependent kinase (CDK) complex [1].

Unicellular eukaryotic organisms, such as the budding yeast $S$. cerevisiae, only have limited genes encoding cyclins and CDKs. In contrast, multicellular organisms, including mammals, express multiple different CDKs, which are often able to bind more than one cyclin, giving rise to a range of distinct cyclin-CDK complexes, each of their activities characterizing discrete phases of the cell cycle.

The activity of CDKs is regulated on multiple transcriptional and post-translational levels. CDK activity is, for instance, extensively controlled through activating (e.g. by the CDK-activating kinase (CAK) [2, 3]) and inhibitory phosphorylation (e.g. by the Wee1 and Myt1 kinases [4-6]. However, probably the most important regulatory layer of oscillating CDK activity relates to the controlled production and down-regulation of their cyclin partners, as CDKs are typically only active when bound to a cyclin. The controlled production and down-regulation of cyclins also holds the key as to how the cell cycle can only progress in a unidirectional fashion, and how S-phase and mitosis are limited to once per cell cycle [7]. The timely destruction of cyclin proteins is accounted for by ubiquitin ligation and ensuing degradation by the $26 \mathrm{~S}$ proteasome [8]. Ubiquitination of mitotic A- and B-type cyclins is accounted for by the anaphase-promoting complex/cyclosome (APC/C), a multi-subunit E3 ubiquitin ligase. During $S$ and $G_{2}$ phase of the cell cycle, the APC/C remains inactive, which allows the gradual accumulation of mitotic cyclins $[9,10]$. Once cells have entered mitosis and have properly aligned their chromosomes, the APC/C is activated and ubiquitinates- 
among other substrates-mitotic cyclins, and thereby constitutes an important part of the mitotic exit machinery, allowing cells to complete cell division. Through this mechanism, the APC/C forms an integral part of the machinery that ensures periodicity of the cell cycle [8].

Recent evidence has shown that the APC/C also performs additional functions, for instance in response to DNA damage. In this review, we provide a short background on the APC/C and the cellular response to DNA damage. Subsequently, we summarize the current literature on APC/C-Cdh1 activation after DNA damage, and how this affects DNA repair, checkpoint duration and cell fate.

\section{Structure and function of the APC/C-Cdh1}

The anaphase-promoting complex/cyclosome (APC/C) is an exceptionally large multimeric E3 ubiquitin ligase, belonging to the ring/cullin subfamily of ubiquitin ligases $[11,12]$. As it was identified as a protein complex from clam egg extracts that can degrade mitotic cyclins, it was named 'cyclosome' [13]. Likewise, a similar 20S complex was biochemically purified from Xenopus extracts based on its ability to facilitate cyclin B destruction and to promote anaphase, hence it was named the 'anaphase-promoting complex' (APC) [14]. In parallel, genetic analysis of mutant yeast strains led to the identification of APC components in budding yeast and fission yeast that are required for degradation of Cyclin B and Securin during the metaphase-to-anaphase transition [15-17]. Currently, the term and abbreviation anaphase-promoting complex/cyclosome $(\mathrm{APC} / \mathrm{C})$ is used, which also prevents confusion with the frequently mutated tumor suppressor gene $A P C$, encoding the Adenomatous Polyposis Coli gene product.

The APC/C is composed of 14 different subunits in mammalian cells (Table 1), whereas alternative conformations with species-specific subunits have been identified (e.g. the budding yeast-specific subunit APC9, and the fission yeast-specific subunit APC14) $[11,12,18]$. Additionally, the $\mathrm{APC} / \mathrm{C}$ requires binding to a co-activator (either $\mathrm{Cdc} 20$ or Cdh1) for catalytic activity and for substrate recognition. Reconstruction using cryo-electron microscopy recently yielded a complete overview of the 3D assembly of the APC/ C [12], and confirmed the triangular 'shell-like' shape (Fig. 1), that was proposed based on earlier structural studies. Concerning the stoichiometry of the APC/C, five subunits are present in two copies (APC12 as well as the four tetratricopeptide-repeat (TPR)-containing subunits APC3, APC6, APC7 and APC8), whereas the other subunits are only present in one copy $[11,19]$. This conformation leads to an assembly of 19 subunits with a size of $1.22 \mathrm{MDa}$.

The 'back' of the APC/C complex is also referred to as the 'TPR' lobe, as it harbors the four APC/C subunits with conserved tetratricopeptide-repeat motifs (APC3, APC6, APC7 and APC8) as well as the accessory protein APC12. TPR motifs are widely found and consist of 34 amino acids, which promote protein-protein interactions and thereby are often involved in the structural organization of

Table 1 Human APC/C subunits and co-activators

\begin{tabular}{llll}
\hline APC/C subunits & Alternative names & Human gene name & Function \\
\hline APC1 & - & $A N A P C 1$ & Scaffold, PC repeats \\
APC2 & - & $A N A P C 2$ & Catalytic core-cullin subunit \\
APC3 & Cdc27 & $C D C 27$ & Scaffold with TPR motifs \\
APC4 & - & $A N A P C 4$ & 'Platform' subunit \\
APC5 & - & $A N A P C 5$ & 'Platform' subunit \\
APC6 & Cdc16 & CDC16 & Scaffold with TPR motifs \\
APC7 & - & ANAPC7 & Scaffold with TPR motifs \\
APC8 & Cdc23 & CDC23 & Scaffold with TPR motifs \\
APC10 & Doc1 & ANAPC10 & Substrate recognition \\
APC11 & - & ANAPC11 & Catalytic core-RING H2 domain \\
APC12 & Cdc26 & CDC26 & Stabilizing APC6 \\
APC13 & - & ANAPC13 & Stabilizes APC3, APC6 and APC8 \\
APC15 & - & $A N A P C 15$ & Mediated Cdc20/MCC turnover \\
APC16 & - & ANAPC16 & TPR subunit \\
\hline Co activators & Alternative names & Human gene name & Function \\
\hline Cdc20 & P55-Cdc20 & CDC20 & Substrate recruitment/APC/C activation \\
Cdh1 & Fizzy-related, Hct1 homolog & FZR1 & Substrate recruitment/APC/C activation \\
\hline
\end{tabular}

Proteins names, common alternative names, human gene symbols and designated functions of APC/C subunits and co-activators are listed 


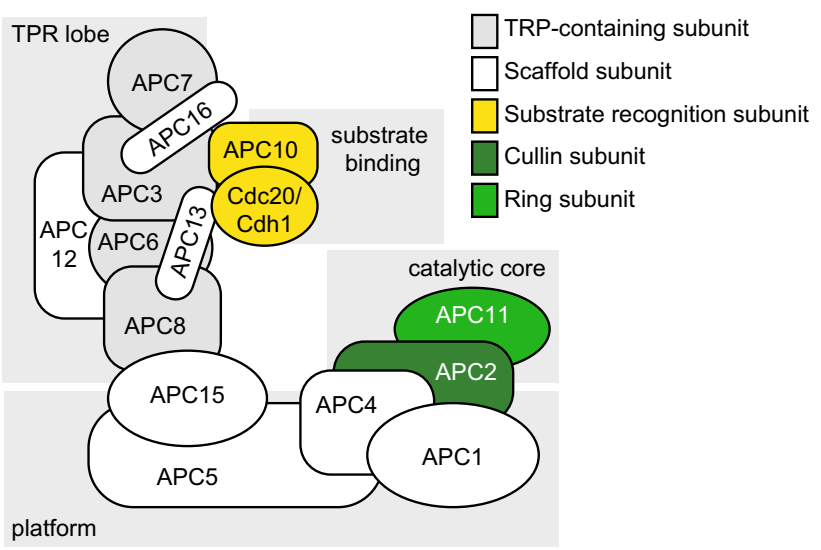

Fig. 1 The molecular composition of the APC/C. The subunits of the mammalian APC/C are indicated. APC3, APC6, APC7 and APC8 contain tetracopeptide-repeat (TPR) domains, and together with APC12 form the TPR lobe. APC1, APC4 and APC5 form the 'platform' domain of the APC/C. The catalytic core is composed of APC11 (Ring) and APC2 (Cullin). APC10 together with one of the co-activators Cdc20/Cdh1 forms the degron-recognition domain

multimeric protein complexes. The TPR-containing subunits within the APC/C are bound and correctly ordered by the APC16 and APC13 subunits (Fig. 1) [12]. The 'platform' part of the APC/C is formed by the APC1, APC4 and APC5 subunits [12, 20, 21]. The actual catalytic subunits APC2 (cullin) and APC11 (ring) are located at the periphery of the platform, in close proximity to the degronrecognition module, consisting of APC10 and Cdh1 or Cdc20 (Fig. 1). Binding of the Cdh1/Cdc20 co-activators to the $\mathrm{APC} / \mathrm{C}$ induces conformational changes in the threedimensional structure of the APC/C [12], and explains why complex formation between $\mathrm{APC} / \mathrm{C}$ and $\mathrm{Cdh} 1 / \mathrm{Cdc} 20$ elevates catalytic activity [22].

\section{Activation of the APC/C}

Activity of the APC/C is regulated predominantly through binding to its co-activators $\mathrm{Cdc} 20$ and $\mathrm{Cdh} 1$, as well as through interaction with its inhibitors Emi1 and the MCC $[11,19]$.

The co-activators $\mathrm{Cdc} 20$ and $\mathrm{Cdh} 1$ have a dual role in APC/C-mediated degradation of substrates. Firstly, the WD40 motif in their C-terminal parts is involved in recruitment of substrates to the APC/C. Secondly, binding of $\mathrm{Cdc} 20$ or Cdh1 induces a conformation change in the APC/ $\mathrm{C}$ to promote ubiquitination. The $\mathrm{Cdc} 20$ co-activator associates with the APC/C upon mitotic entry, and remains associated until the metaphase-to-anaphase transition. At that point, $\mathrm{Cdc} 20$ is replaced by $\mathrm{Cdh} 1$, which remains associated with the APC/C up until $\mathrm{G}_{1}$ phase (Fig. 2). Interaction of co-activators with the $\mathrm{APC} / \mathrm{C}$ is controlled by Cdk1-mediated phosphorylation. Cdc20 phosphorylation by $\mathrm{Cdk} 1$ is essentially required for its association with the APC/
$\mathrm{C}$ and for stimulation of APC/C activity [23, 24]. The effect of CDK-mediated phosphorylation on Cdh1, in contrast, is completely opposite. Cdk1-phosphorylated Cdh1 cannot associate with the APC/C, which effectively limits APC/CCdh1 activity until after anaphase onset [23, 24].

Prior to complex formation between Cdh1 and the APC/ C, Cdk1-mediated phospho-groups need to be removed, a process that requires phosphatase activity. In budding yeast, Cdh1 dephosphorylation is governed by the Cdc14 phosphatase, under control of the mitotic exit network pathway $[25,26]$. In human cells, two Cdc14 isoforms exist, Cdc14A and Cdc14B, and only the Cdc14B isoform appears to be involved in mitotic dephosphorylation of Cdh1 [27] (Fig. 2).

In addition to co-activator binding, which is essential to promote $\mathrm{APC} / \mathrm{C}$ activation, the $\mathrm{APC} / \mathrm{C}$ is also subject to inhibition by Emi1 [28]. During interphase, Emi1 serves as a pseudo-APC/C substrate as it binds the APC/C at the D-box receptor and simultaneously interacts with Cdh1 without being degraded. By doing so, Emil occupies the substrate binding site of the APC/C to allow accumulation of cyclins [29] (Fig. 2). Upon mitotic entry, phosphorylation of Emi1 by Polo-like kinase-1 (Plk1) creates a phospho-degron on Emi1, which facilitates degradation of Emi1 by the Skp1-Cullin1 F-box (SCF)- $\beta$-TrCP complex $[28,30]$. Degradation of Emil in early mitosis does not actually appear to be required to allow APC/C activation during mitosis, as Emil depletion does not interfere with cyclin degradation during mitosis [31]. The main function of Emi1 therefore appears to be safeguarding cyclin accumulation prior to mitosis.

Another inhibitor of the APC/C is the mitotic checkpoint complex (MCC). Until all chromosomes are properly attached to microtubules from the opposing poles of the mitotic spindle, Mad1-Mad2 heterodimers are formed at unattached kinetochores. Once formed, the Mad1-Mad2 dimer induces a change in conformation of a separate Mad2 copy to produce 'closed-Mad2' (C-Mad2) [32]. C-Mad2, in conjunction with BubR1 and Bub3, binds and thereby blocks Cdc20. This latter complex is referred to as the MCC, and prevents premature mitotic exit, by inhibiting APC/C-Cdc20-mediated degradation of Cyclin B and Securin until all chromosomes have been properly attached to the mitotic spindle [19, 33-36].

Although, clearly, the APC/C is controlled through binding to activators and inhibitors, also post-translational control by phosphorylation is involved in its regulation. Multiple subunits of the APC/C are phosphorylated at mitotic onset, including by mitotic kinases Cdk1 and Plk1 [37-39]. Cdk1-mediated phosphorylation events are required for activation of the APC/C-Cdc20, but seem to be dispensable for APC/C-Cdh1 activity [24, 39]. By contrast, phosphorylation of APC/C subunits by Plk1 does not 


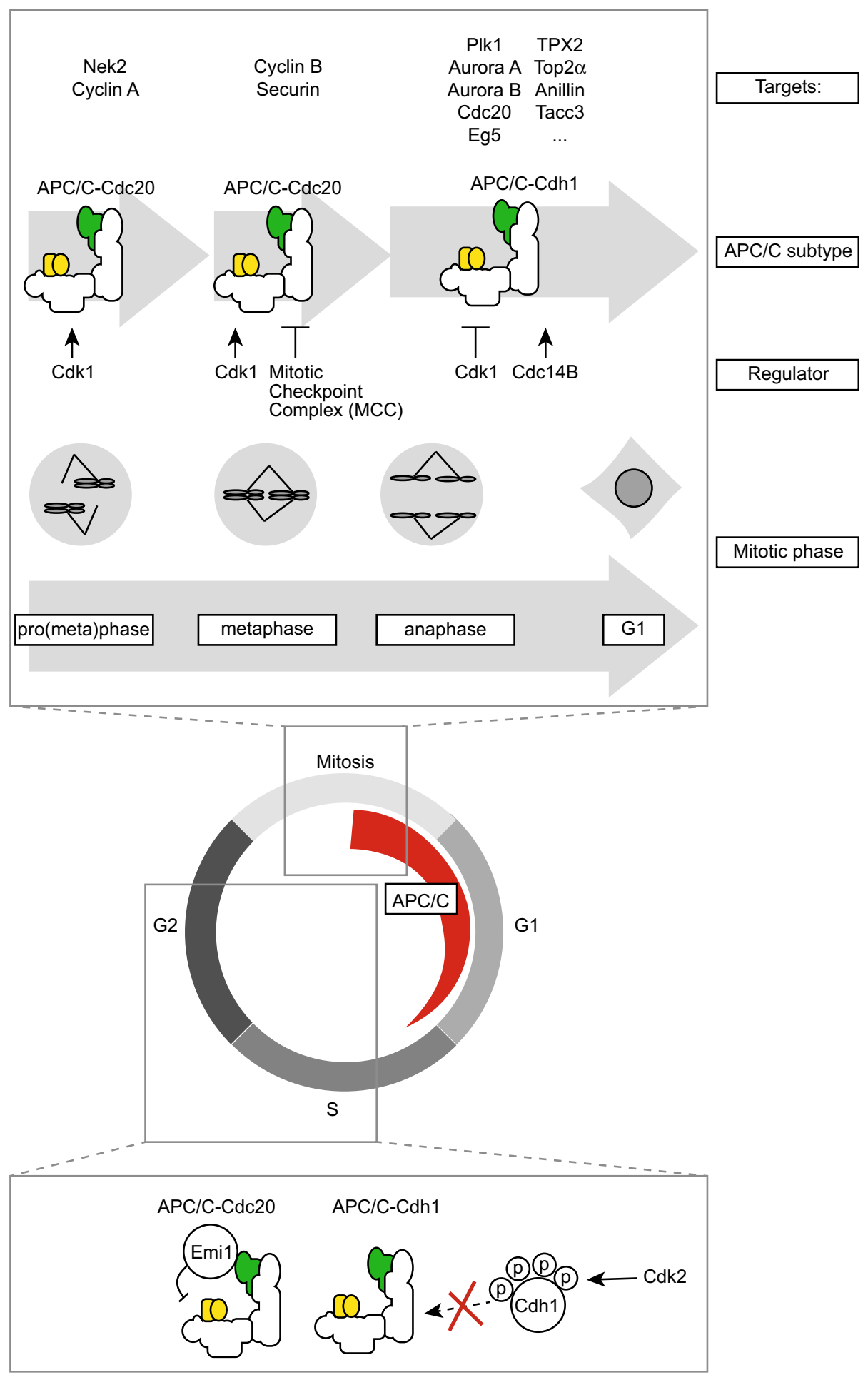

Fig. 2 Three waves of APC/C activation during mitosis. The APC/C is activated during mitosis and remains active up until $\mathrm{G}_{1}$ phase. Three independent waves of APC/C activity can be distinguished. (1) APC/C-Cdc20 activity during prometaphase, which is unaffected by the spindle checkpoint, (2) APC/C-Cdc20 activity in metaphase,

appear to influence the activation of the APC/C-Cdc20 [37, 40, 41]. Nevertheless, phosphorylation of APC/C, as well as its co-activators and inhibitors appears to be a key which is under control of the spindle checkpoint, (3) APC/C-Cdh1 activity, which commences during anaphase onset. Identified substrates of each of the APC/C entities are indicated. Interphase activation of the $\mathrm{APC} / \mathrm{C}$ is precluded by Emil and Cdk2-mediated phosphorylation of Cdh1

mechanism in controlling the timing of its activation. And thus, mitotic kinases act in bifurcated ways to ensure rapid activation of the APC/C during mitotic entry. 


\section{Recognition of APC/C substrates}

The above mentioned layers of regulation make that three different phases of APC/C activity can be distinguished, and these phases are best characterized by degradation kinetics of APC/C substrates (Fig. 2). APC/C substrates require 'degrons', specific amino acids sequences that are recognized by APC/CCdc20 or APC/C-Cdh1, to be efficiently degraded. Most APC/ C substrates contain one or more D-boxes (RXXLXX[I/V]XN) or KEN boxes (KENXXX[N/D]) [42, 43].

A first wave of APC/C activity is observed upon mitotic entry, and depends on the Cdc20 co-activator. During prometaphase, the Cdc20-activated APC/C degrades Cyclin A and the NIMA-related kinase Nek2A [44-47]. Of note, degradation of Cyclin A and Nek2A depends on $\mathrm{Cdc} 20$, but is not subject to regulation by the spindle checkpoint. How exactly these early APC/C-Cdc20 targets escape regulation by the MCC is not entirely clear, but the use of alternative degrons appears involved.

A second wave of APC/C-Cdc20 activity occurs upon silencing of the spindle checkpoint, and mediates the degradation of Cyclin B and Securin. These two APC/C targets are the only essential targets for cell proliferation [48]. Degradation of Securin is required for sister chromatid separation $[49,50]$, whereas degradation of Cyclin B is required for exit from mitosis [51-54]. In line with this notion, multiple APC genes as well as the CDC20 gene are essential, whereas Cdh1 is non-essential for survival of individual cells [55-60].

Once the levels of Cyclin B are decreased below a critical level, Cdk1 activity seizes and Cdh1 is allowed to initiate a third wave of APC/C activity. The APC/C-Cdh1 is activated during mitotic exit and targets a range of proteins, including mitotic cyclins regulators of mitotic spindle organization, as well as essential S-phase components $[11,19]$. Through suppressing mitotic cyclins, the APC/C-Cdh1 is an important factor in the decision to reenter a new round of cell division, and ultimately controlling cell fate [61]. In line with this notion, absence of Cdh1 leads to aberrant up-regulation of Cyclin A levels and results in premature initiation of replication. So, although the APC/C-Cdh1 is not essential for cell division of individual cells, this does not mean that the APC/C-Cdh1 does not fulfil an important function, as is also underscored by the lethal phenotype of the Cdh1 knockout mouse [62].

\section{Cell cycle regulation in situations of DNA damage}

As mentioned above, the cell cycle machinery warrants the timely coordination of the various molecular events in which duplication and distribution of chromosomes over daughter cells is managed. In order to ensure that cells are protected against genomic insults, the cell cycle machinery is susceptible to external cues. When DNA is damaged, for instance due to intrinsic factors such as critically short telomeres or replication stress or extrinsic sources including ionizing radiation, cells activate the 'DNA damage response' (DDR) [63, 64].

The DDR detects DNA damage, and coordinates a cell cycle arrest with the repair of damaged DNA. Situated upstream in the DDR response, several protein complexes can detect various aberrant DNA structures. For instance, the Mre11/Rad50/Nbs1 (MRN) complex binds the ends of double strand DNA breaks (DSBs) [65], whereas the Rad9Rad1-Hus1 (9-1-1) complex is loaded onto DNA with structural abnormalities, for instance after UV exposure or stalled replication [66]. Subsequent to detection of DNA lesion, checkpoint kinases are activated. In response to DNA DSBs, the Ataxia Telangiectasia Mutated (ATM) kinase is activated. Conversely, in response to replication stalling, or otherwise generated stretches of single-stranded DNA, the ATM and Rad3-related (ATR) kinase is activated. Both ATM and ATR are members of the PI(3)Kinase-related kinase (PIKK) family, and can phosphorylate an extensive array of substrates, including DNA repair proteins, the RNA translation machinery and metabolic regulators [67]. More importantly, ATM and ATR link the detection of DNA damage to stalling of the cell cycle.

Upon generation of DNA DSBs, ATM phosphorylates and thereby activates the checkpoint kinase Chk2 [68]. In turn, Chk2 phosphorylates members of the Cdc25 phosphatase family which leads to their inhibition [69, 70]. Under normal conditions, the Cdc25 phosphatases counteract the Myt1 and Wee1 kinases, by removing the inhibitory phosphate groups on tyrosine 15 (Y15) and threonine 14 (T14) in Cdk1 and Cdk2 [1, 4-6, 71]. Consequently, the ATM/Chk2 axis within the DDR prevents Cdc25 activation and keeps Cdk1/2 in a phosphorylatedinactive-state to prevent cell cycle progression. Likewise, ATR phosphorylates the Chk1 checkpoint kinases to achieve similar inactivation of the Cdc25 phosphatases [72-75].

The kinetics of these kinase-driven DDR signaling axes are fast, and mediate a rapid arrest of cell cycle progression within minutes after DNA damage induction [76]. This fast-acting part of the DDR is complemented with a delayed, yet robust, transcriptional pathway. ATM, as well as the ATR, Chk1 and Chk2 kinases, phosphorylate multiple residues within the $\mathrm{N}$-terminus of the p53 transcription factor [77-81]. In parallel, the E3 ubiquitin ligase MDM2, which under physiological conditions ubiquitinates and thereby marks p53 for proteasomal degradation [82], is also phosphorylated by ATM. ATM- or ATR-mediated phosphorylation of MDM2 prevents the 
association between p53 and MDM2, and leads to stabilization of p53 [83, 84]. In turn, p53 promotes transactivation of its many target genes, including the cyclin-dependent kinase inhibitor (CKI) p2 $1^{\text {cip/waf }}[85,86]$ and the cell cycle checkpoint protein Gadd45 [87, 88]. Although this transcriptional DNA damage response requires hours to be installed, its downstream effects can last for days. The combination of a kinase-driven fastacting DDR axis with a delayed transcriptional DNA damage response thus constitutes a robust cellular reaction to maintain genomic integrity. Temporarily arresting cell cycle progression can provide time for repair of DNA lesions, after which cells can silence checkpoints to restart the cell cycle $[89,90]$.

When the levels of DNA damage are beyond repair, however, affected cells need to be permanently arrested (senescence) or eliminated through programmed cell death (apoptosis). Failure to do so is associated with increased tumorigenesis [91]. How cells exactly make the decision to enter a permanent cell cycle arrest after DNA damage is unclear. Recent data have shown that entrance into senescence is dependent on the level of DNA damage, is p53dependent and can happen both in $\mathrm{G}_{1}$ and $\mathrm{G}_{2}$ cells $[92,93]$.

\section{Recently emerging roles of the APC/C-Cdh1 in the response to DNA damage}

In line with a role of the APC/C-Cdh1 in degradation of mitotic regulators, inactivation of the $C d h 1$ locus in chicken DT40 cells, resulted in accumulation of mitotic cyclins in $\mathrm{G}_{1}$ cells [94]. Unexpectedly, Cdhl knock-out cells failed to maintain a DNA damage-induced $\mathrm{G}_{2}$ cell cycle checkpoint arrest [94]. These data suggested for the first time that the APC/C-Cdh1 also has a function in $\mathrm{G}_{2}$ phase of the cell cycle. This role, however, seems to be restricted to situations, in which there is DNA damage. Indeed, upon irradiation, $\mathrm{Cdh} 1$ was shown to associate with the $\mathrm{APC} / \mathrm{C}$, using co-immunoprecipitation assays in cell line models from several species [94]. Moreover, purified APC/C from irradiated $G_{2}$ cells was activated when assessed using in vitro ubiquitination assays towards $\mathrm{Cdc} 20$ [94].

Under normal conditions, the APC/C-Cdh1 is unable to ubiquitinate substrates in $\mathrm{G}_{2}$ phase and early mitosis. This is achieved through multiple mechanisms. Firstly, CDKmediated phosphorylation of $\mathrm{Cdh} 1$ occurs on different residues prior to the metaphase-to-anaphase transition, and these phosphorylation events prevent association of Cdh1 with the APC/C [23, 95]. Importantly, a Cdh1 mutant in which CDK phosphorylation sites were removed activated the APC/C already in S-phase [9, 23]. Likewise, depletion of Cyclin A also prematurely activated the APC/C-Cdh1, suggesting that a Cyclin $\mathrm{A} / \mathrm{CDK}$ complex is required to keep APC/C-Cdh1 inactive during interphase [9]. Secondly, as also explained previously, the $\mathrm{APC} / \mathrm{C}$ is kept inactive during $S$ and $G_{2}$ phase by Emi1 $[29,96]$. Emi1 is expressed from late $\mathrm{G}_{1}$ onwards, and sterically inhibits the $\mathrm{APC} / \mathrm{C}[10,29]$. Only during mitotic entry, Emi1 is degraded by the SCF- $\beta$-TrCP $[28,31,97]$. The impact of Emi1-mediated APC/C inhibition becomes apparent after Emil depletion: Cyclins A and B do not accumulate, and cells do not initiate S-phase, nor enter mitosis [10, 96].

\section{Activation of the APC/C-Cdh1 in response to DNA damage: How is it accomplished?}

Although genetic and biochemical evidence was provided which indicated that the APC/C-Ch1 can be activated in response to DNA damage, it is not entirely clear how this is accomplished mechanistically. Most evidence so far points at regulation of the phosphorylation status of Cdh1. The activity of cyclin/CDK complexes is down-regulated after activation of the DDR, through rapid inactivation of the Cdc25 phosphatases that under normal circumstances activate CDKs. However, the level of CDK inactivation that the kinase-driven DDR axis accomplishes does not seem to be sufficient for APC/C-Cdh1 activation [98]. Rather, the p53/p21 transcriptional DDR axis is required for APC/C-Cdh1 activation, since deletion of TP53 or CDKN1A (encoding p21) abrogated APC/C-Cdh1 activation after DNA damage [98]. Whether the function of p53 in this context is solely due to lower CDK activity is unclear, as it also leads to down-regulation of Emil and could through this effect also promote activation of the APC/C-Cdh1 [98].

Besides regulation of CDK kinase activity, the phosphatase that removes CDK-mediated phosphorylation groups appears differentially regulated upon DNA damage as well. In budding yeast, the Cdc14 phosphatase is involved in reversing CDK phosphorylation events during anaphase [25], controlled by the Mitotic Exit Network (MEN) pathway [99]. As part of this mechanisms, Cdc14 is released from the nucleolus to promote Cdh1 dephosphorylation and ensuing APC/C activation [25, 100]. Human cells contain two $\mathrm{Cdc} 14$ orthologues: $\mathrm{Cdc} 14 \mathrm{~A}$ and Cdc14B. Of these two, Cdc14B is localized to nucleoli, from which it is released during mitosis [27]. In contrast to yeast, however, Cdc14B in human cells is not essentially required for mitotic exit [27]. Interestingly, in $G_{2}$ cells Cdc14B is released from the nucleolus in response to DNA damage [101, 102].

Combined, it seems that three events contribute to APC/ C-Cdh1 activation in $\mathrm{G}_{2}$ cells: (1) down-regulation of CDK activity in response to DDR activation, (2) p53-dependent 
inactivation of $\mathrm{APC} / \mathrm{C}$ inhibitor Emil, and (3) the translocation of Cdc14B phosphatase from the nucleolus to the nucleoplasm. Many questions about the exact molecular wiring of these pathways, however, remain unsolved [102]. For instance: is Emil degradation required for APC/ C-Cdh1 activation? Another question relates to how Cdc14B is released from the nucleolus in response to DNA damage. More interestingly perhaps; it remains unclear whether these various events are connected.

Although unexplored, a more direct way of $\mathrm{APC} / \mathrm{C}$ regulation concerns direct modification of APC/C subunits in response to DNA damage, through direct phosphorylation by ATM/ATR. In a large proteomics study to identify ATM and ATR substrates, APC12 was found to be phosphorylated on Ser-78 in response to ionizing radiation [67]. Although it is unclear what the functional impact of this phosphorylation event is, this residue appears conserved in mammals, but not in all vertebrates, such as chicken and frog (data not shown). Although Cdc26/APC12 does not appear to be directly involved in catalytic activity of the $\mathrm{APC} / \mathrm{C}$, modification of the APC/C in response to DNA damage might alter the conformation of the $\mathrm{APC} / \mathrm{C}$, or possibly have an impact on its activity or substrate specificity.

\section{Regulation of the $\mathrm{G}_{2} / \mathrm{M}$ checkpoint by the $\mathrm{APC} / \mathrm{C}$ - Cdh1}

Activation of the APC/C-Cdh1 appears to contribute to the maintenance of a DNA damage-induced $\mathrm{G}_{2} / \mathrm{M}$ cell cycle checkpoint. Cdh1 inactivation in DT40 chicken cells lead to premature checkpoint termination [94]. Although the APC/C-Cdh1 has many reported targets, the defects in $\mathrm{G}_{2} /$ $M$ checkpoint maintenance were attributed to defective down-regulation of Plk1. Out of 15 assessed APC/C-Cdh1 targets, only Plk1 showed APC/C-Cdh1-dependent degradation in response to DNA damage. Specifically, expression of a Plk1 mutant that cannot be targeted by the APC/C resulted in enhanced mitotic entry in the presence of DNA damage [101].

The surprising finding that not all APC/C-Cdh1 targets are down-regulated after DNA damage, was at least in part explained by the action of the deubiquitinating (DUB) enzyme USP28. The APC/C-Cdh1 target Claspin, for instance, is protected from APC/C-mediated down-regulation by USP28 [101], and also 53BP1 and Chk2 were reported to be stabilized by USP28 upon DNA damage [103]. An additional explanation for selective substrate engagement of the APC/C-Cdh1 would be the presence of two distinct pools of APC/C [104]. One pool presumably is inactive in $\mathrm{G}_{2}$, regardless of the presence of DNA damage, by virtue of inhibition by Emil. A second pool would be inactive in $\mathrm{G}_{2}$ cells due to $\mathrm{CDK}$-mediated phosphorylation. Only this second pool presumably becomes active upon DNA damage, due to Cdc14B-mediated dephosphorylation of Cdh1 and/or down-regulation of CDK activity [104]. This model is supported by the observation that USP28 depletion does not lead to general degradation of APC/CCdh1 targets, and the observation that Emi1 association with the APC/C does not appear to be controlled by DNA damage [101].

The APC/C-Cdh1 also targets other proteins that are crucial for the $G_{2} / M$ transition, which could explain the effects of Cdh1 depletion on checkpoint maintenance. The MEF2C and FoxM1 transcription factors, for instance, are Cdh1 targets and promote the expression of multiple cell cycle genes including 14-3-3 $\gamma$, Gadd $45 b$ and p21 for MEF2C; and Cyclin B1 and Plk1 for FoxM1 [105-107]. Whether MEF2C and FoxM1 are degraded in a Cdh1-dependent fashion in response to DNA damage, however, is not known. Another APC/C-Cdh1 target is the Wip1 phosphatase [108]. Wip1 can reverse ATM/ATR-mediated phosphorylation groups, for instance on $\mathrm{H} 2 \mathrm{AX}$ and p53, and is involved in the restart of the cell cycle when DNA has been repaired [109-112]. Proteolytic down-regulation of Wip1 could aid in maintaining a cell cycle arrest in situations of DNA damage, although this hypothesis has yet to be confirmed experimentally.

\section{Regulation of DNA repair by the APC/C-Cdh1}

In addition to its effects on $\mathrm{G}_{2}$ checkpoint behavior, the APC/C-Cdh1 has also been implicated in modulating DNA repair.

Concerning the repair of DNA double strand breaks (DSBs), cells can choose between two fundamentally different repair pathways. Repair through error prone nonhomologous end-joining (NHEJ) can occur throughout the cell cycle, and ligates DNA ends in a sequence-independent fashion [113]. Alternatively, cells can repair DSBs using homologous recombination (HR). Since this process uses sister chromatids as a template for error-free repair, $H R$ is restricted to $S / G_{2}$ phase of the cell cycle [114]. A key step in HR is the formation of single-stranded (ss)DNA through $5^{\prime}$-to- $3^{\prime}$ end resection. This process is facilitated by the MRN complex, in conjunction with CtIP [115]. As DNA ends with long ssDNA tails are not substrates for end-joining repair, the process of DNA end resection is the key decisive point where repair is committed to HR repair.

In fission yeast, the Rad54 homolog rhp54 was shown to be a target of the APC/C-Cdh1 [116]. Rad54 is a DNAdependent ATPase and is critically required for HR. Expression of a non-degradable Rhp54 mutant leads to aberrant HR and to increased sensitivity to a range of DNA 
damaging agents, including bleomycin and UV [116]. However, no APC/C-dependent degradation of the $S$. cerevisiae $\operatorname{Rad} 54$ nor human $\operatorname{Rad} 54 \mathrm{~A}$ or $\operatorname{Rad} 54 \mathrm{~B}$ was observed, suggesting the observed phenotype is speciesspecific [116]. Upstream in the HR pathways, the ReceptorAssociated Protein 80 (Rap80) forms a complex with Brca1, and facilitates the recruitment of Brcal to sites of DNA damage [117]. During mitotic exit, Rap80 is degraded in an APC/C-dependent fashion, which is thought to prevent illegitimate recombination during $G_{1}$ phase of the cell cycle [118].

In a proteomic screen, the homologous recombination DNA repair protein CtIP was identified as a APC/C-Cdh1 target [119]. Specifically, CtIP was down-regulated in an APC/C-Cdh1-dependent manner, both during mitotic exit as well as in response to DNA damage. Notably, expression of a non-degradable CtIP mutant resulted in extended retention of CtIP at sites of DNA damage, caused elevated levels of DNA end resection, and ultimately interfered with normal DNA repair through recombination [119]. From these data, it appears that $\mathrm{APC} / \mathrm{C}$ activation at late time points after DNA damage is required for proper DNA repair. This observation is in line with data from Cdc14B knockout cells. Loss of Cdc14B, which should lead to an inability to activate the APC/C-Cdh1 in response to DNA damage, resulted in defective DNA repair [120].

The APC/C-Cdh1 has also been implicated in controlling replication. Prior to S-phase initiation, the deubiquitinating enzyme USP1 is down-regulated by the APC/C-Cdh1, which allows PCNA to be mono-ubiquitinated in response to UV [121]. Thus, the APC/C-Cdh1 is required to equip cells with the ability to deal with potential replication-blocking lesions in the ensuing S-phase. During replication stress, exposed ssDNA activates the ATR kinase, which phosphorylates the Rad17 protein $[122,123]$. Subsequently, $\operatorname{Rad} 17$ is thought to be involved in the loading of the Rad9-Rad1-Hus1 (9-1-1) checkpoint-sliding clamp onto DNA, as well as the activation of the Claspin/Chk1 complex to facilitate cell cycle checkpoint activation and repair [124, 125]. Rad17 was shown to be degraded in response to UV exposure, in an APC/C-Cdh1-dependent fashion [126]. Rather than controlling DNA repair, damage-induced degradation of Rad17 appears to be required for cell cycle re-entry [126].

Other APC/C-Cdh1-mediated effects during the response to replication stress include the stabilization of the Cdc7, as well as its co-factor: activator of S-phase kinase (ASK, also referred to as Dfb4). In response to a hydroxyurea-induced replication arrest, Cdc7 and ASK are stabilized. Cdc7/ASK activity, in turn, stimulates DNA lesion bypass, also known as translesion synthesis (TLS) [127]. Mechanistically, Cdh1 was shown to promote its own degradation, in a manner that was stimulated by Chk1.
How exactly Chk 1 promotes the inactivation of Cdh1 is not clear [127]. Also the APC/C-Cdh1 target PCNA-associated factor-15 (p15-PAF) is involved in translesion synthesis [128]. In response to replication stalling, p15-PAF is removed from chromatin by proteasomal degradation. Notably, whereas the APC/C-Cdh1 is responsible for p15PAF degradation during $G_{1}$ phase of the cell cycle $[129,130]$, a different ubiquitin ligase is responsible for p15-PAF degradation upon replication stress, as this process is independent of its APC/C destruction boxes [128]. Additional genes that function in S-phase checkpoint pathways, and were shown to be targeted by the APC/C, include Tos 4 and Pdr3 in budding yeast, although the implications of APC/C-mediated regulation of these proteins remains to be established [131].

\section{$\mathrm{APC} / \mathrm{C}$ and $\mathrm{Cdh} 1$ in cancer}

Proper cell cycle control is key in preventing oncogenic transformation. It has been long recognized that $\mathrm{Cdh} 1$ is instrumental in establishing the $\mathrm{G}_{1}$ phenotype after a round of cell division. Cdh1 is required to down-regulate components of the replication and mitotic spindle machinery, and APC/C-Cdh1 activity in $\mathrm{G}_{1}$ phase prevents the accumulation of essential genes for another round of DNA replication. In line with this notion, inactivation of mouse Fzrl gene (encoding Cdh1) prevented the terminal differentiation of neuronal progenitors and resulted in increased proliferation of neuronal stem cells, and conversely, defective neurogenesis $[62,132]$. As a consequence of unscheduled S-phase entry, Cdh1 loss leads to replication stress and ensuing genomic instability [133], a commonly recognized driver of oncogenesis. The latter observations underscore the potential tumor-suppressive function of Cdh1. In good agreement with this model, Cdh1 inactivation leads to the development of several cancers in mice [62], and low Cdh1 expression was observed in multiple cancer cell lines [134]. Also, the PTEN tumor suppressor gene was shown to stimulate association of Cdh1 with the APC/C [135], and hence, the frequently observed loss of PTEN may indirectly result in impaired APC/C-Cdh1 function in cancers. Likewise, the tumor-suppressor sirtuin gene SIRT2 was shown to promote APC/C-Cdh1 function through acetylation of $\mathrm{Cdh} 1$, and again may explain tumor suppressor effects of indirect APC/C-Cdh1 inactivation [136].

Whether the tumor-suppressive function of Cdh1 also involves its role in controlling cell fate after DNA damage is unclear. The observation that APC/C-Cdh1 degrades the histone methyltransferases G9a and GLP in response to DNA damage may point at such a role [137]. Specifically, G9a and GLP are degraded by the APC/C-Cdh1 in a 
Cdc14B- and p21-dependent fashion. Both G9a and GLP are responsible for positioning histoneH3-Lysine-9 mono and di-methyl marks, epigenetic marks of gene silencing. Consequently, DNA damage leads to a global decrease of H3K9 methylation, along with elevated expression of IL6 and IL8, two interleukins that contribute to the senescence phenotype [137]. Importantly, this function of the APC/C was uncovered in response to oncogene-induced replication stress, indicating that Cdh1 prevents outgrowth of cells with oncogene-induced DNA damage. Therapeutically, the increased levels of replication stress in cancer cells with inactivated Cdh1 may create sensitivity to targeted agents that target the replication checkpoint, such as inhibitors of Wee1, ATR or Chk1. In contrast, loss of Cdh1 was recently shown to bypass the dependency of cancer cells on Cdk4/6 [138], indicating that Cdh1 loss may constitute an exclusion criterion for treatment with the recently developed Cdk4/6 inhibitors, or could be a mechanism of acquired resistance to such drugs.

Although some cancer cell lines were reported to have loss of Cdh1 expression, analysis of TCGA data shows that APC/C components and Cdh1 are not commonly inactivated in human cancers. This may point at an essential role of the APC/C and/or APC/C cofactors for the growth of some cancers. Indeed, using an siRNA-based screening, loss of APC/C activity was shown to be synthetic lethal with loss of chromosome cohesion. As a consequence, therapeutic targeting of the APC/C may be beneficial in cohesion-defective cancers [139]. In this context, it is important that small molecule inhibitors of the APC/C have been developed (proTAME and APCin), which in combination block total APC/C activity [140].

\section{Concluding remarks}

Increasingly, the APC/C-Cdh1 is recognized to be involved in the cellular response to DNA damage. The contours of the mechanisms that underlie APC/C-Cdh1 activation have become apparent, with $\mathrm{Cdc} 14 \mathrm{~B}$ and the p53/p21 axis being clearly involved (Fig. 3). Of note, many studies in this area employ high levels of DNA damage, which exceed physiological levels of DNA lesions, and may only reflect situations of cancer treatment with genotoxic agents. Nevertheless, recent studies using oncogene-induced DNA damage and persistent telomere damage confirmed the activation of the APC/C-Cdh1 [137, 141], and established similar genetic requirement, i.e. the presence of $\mathrm{Cdc} 14$ and p53/p21 [137]. Finally, the observation that Cdh1 inactivation leads to high levels of genomic instability and accumulation, underscores the relevance of Cdh1 in maintaining genomic integrity even in unchallenged conditions [61, 62, 142].

Concluding, the APC/C-Cdh1 constitutes one of the effectors pathways of the response to DNA damage. Further research is warranted to better understand the

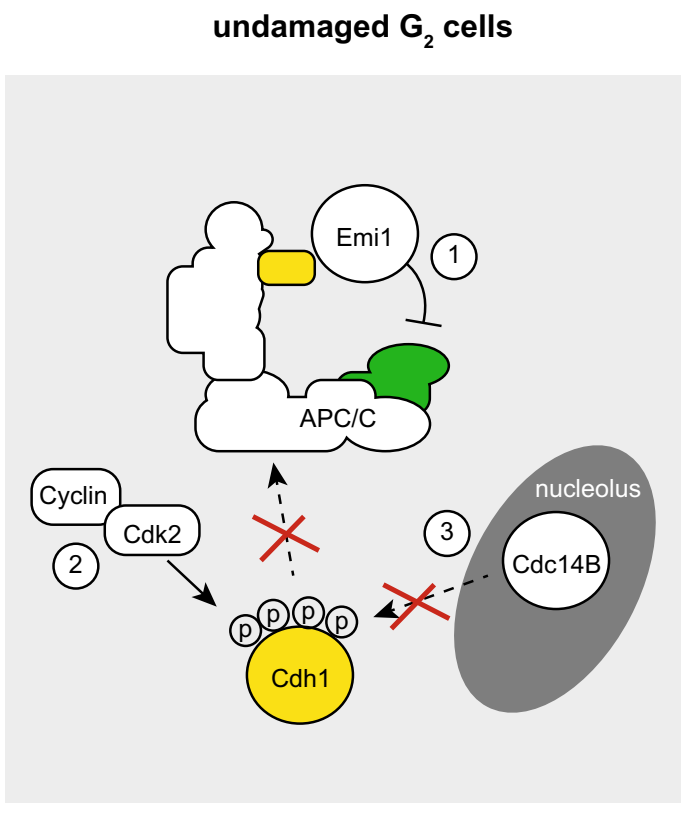

Fig. 3 Roles of the APC/C-Cdh1 in response to DNA damage. During an unperturbed interphase, the APC/C is not active due to (1) binding of Emi1, (2) phosphorylation of $\mathrm{Cdh} 1$ by $\mathrm{Cdk} 2$, and (3) the inability of $\mathrm{Cdc} 14 \mathrm{~B}$ to dephosphorylate Cdh1. In response to DNA damage in $\mathrm{G}_{2}$ cells, (1) the DDR kinases ATM and ATR mediate
$G_{2}$ cells with DNA damage

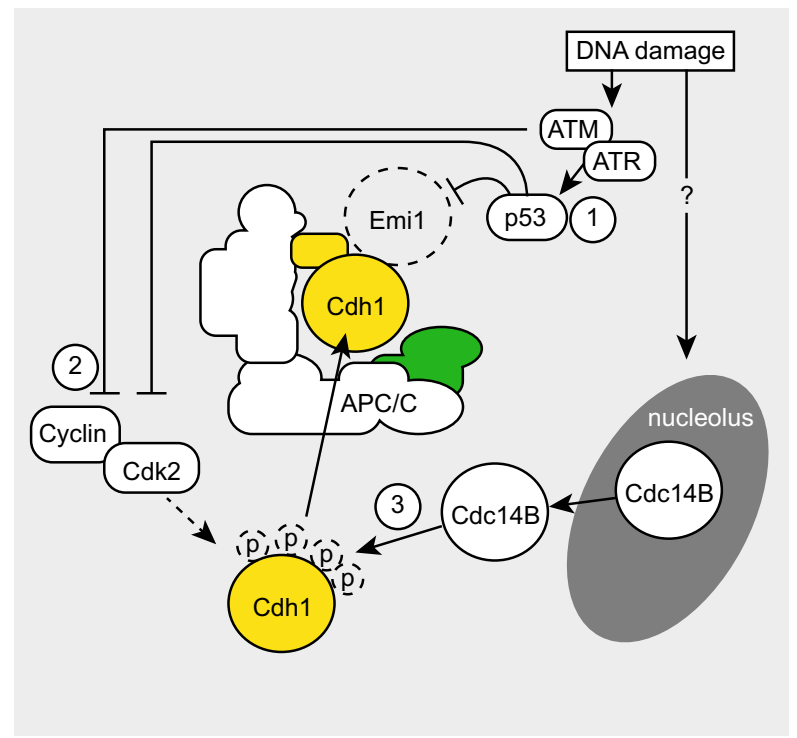

activation of p53, which leads to Emi1 down-regulation. (2) ATM/ ATR and p53 inactivate Cdk2 activity, and 3 Cdc14B is released from the nucleolus through unknown mechanisms. Combined, these mechanisms lead to activation of the APC/C-Cdh1 


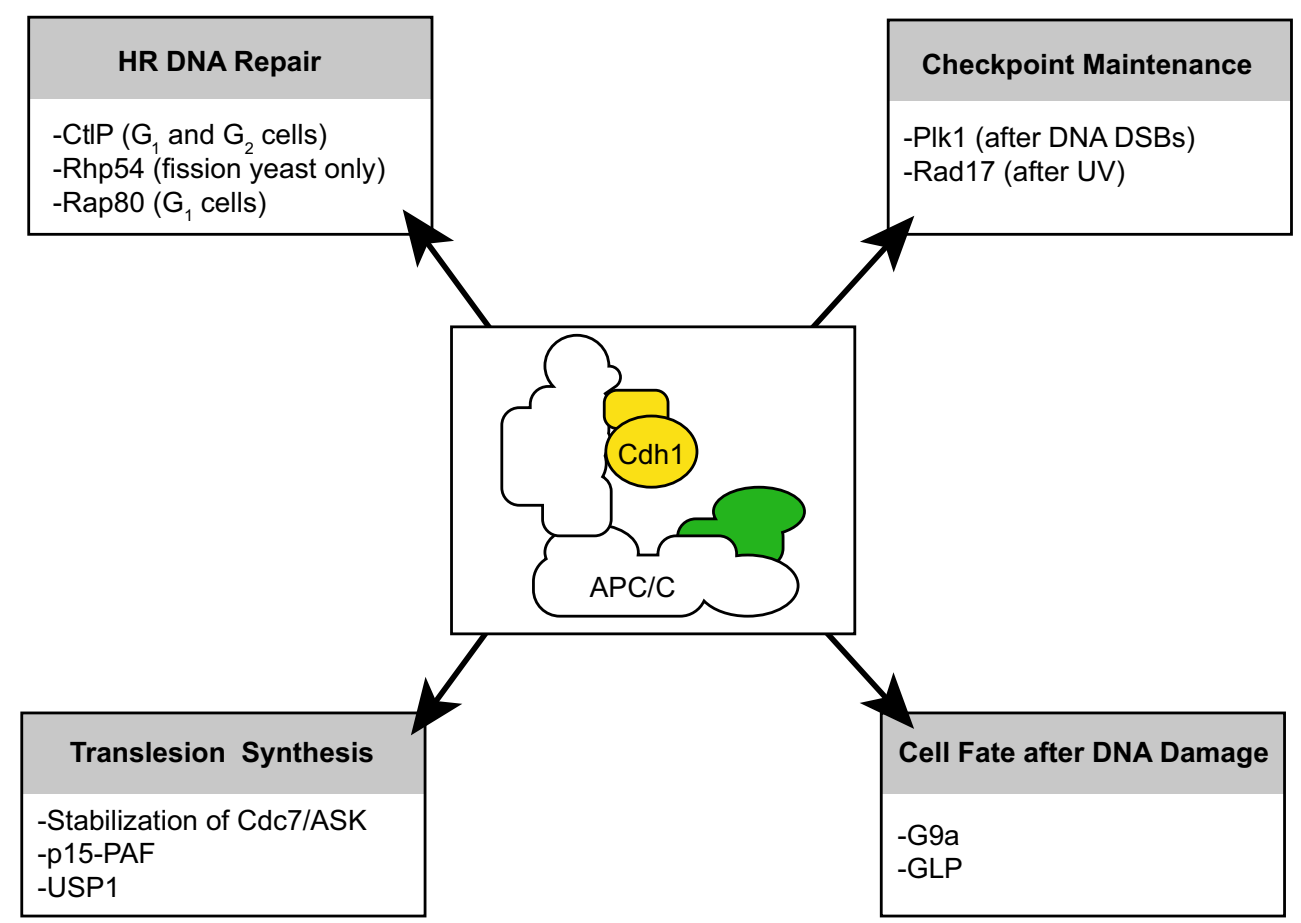

Fig. 4 Functions of the APC/C-Cdh1 in situations of DNA damage. Different function of the APC/C-Cdh1 and its targets are illustrated

mechanisms that underpin APC/C-Cdh1 activation after DNA damage, and which consequences it has (Fig. 4). Uncovering these regulatory mechanisms and phenotypes may provide further insight into how cells are wired to cope with genomic stress, and how these mechanisms may be altered during tumorigenesis and can potentially be exploited during cancer treatment.

Acknowledgements The work of M.A.T.M.v.V. is supported by grants from the Netherlands Organization for Scientific Research (NWO-VIDI 91713334) and the Dutch Cancer Society (RUG20115093). H.R.d.B is supported by the European Research Councel (ERC Advanced Grant ERC-Advanced Grant ERC-2011-293-445). We thank Laura Brands for critically reading the manuscript, and Dr. Gerben Vader for fruitful discussion.

\section{References}

1. Morgan DO (1997) Cyclin-dependent kinases: engines, clocks, and microprocessors. Annu Rev Cell Dev Biol 13:261-291. doi:10.1146/annurev.cellbio.13.1.261

2. Mäkelä TP, Tassan JP, Nigg EA et al (1994) A cyclin associated with the CDK-activating kinase MO15. Nature 371:254-257. doi:10.1038/371254a0

3. Fisher RP, Morgan DO (1994) A novel cyclin associates with MO15/CDK7 to form the CDK-activating kinase. Cell 78:713-724

4. Mueller PR, Coleman TR, Kumagai A, Dunphy WG (1995) Myt1: a membrane-associated inhibitory kinase that phosphorylates Cdc2 on both threonine-14 and tyrosine-15. Science (New York, NY) 270:86-90
5. Russell P, Nurse P (1987) Negative regulation of mitosis by wee1+, a gene encoding a protein kinase homolog. Cell 49:559-567

6. Parker LL, Piwnica-Worms H (1992) Inactivation of the p34cdc2-cyclin B complex by the human WEE1 tyrosine kinase. Science (New York, NY) 257:1955-1957

7. Murray AW (2004) Recycling the cell cycle: cyclins revisited. Cell 116:221-234

8. King RW, Deshaies RJ, Peters JM, Kirschner MW (1996) How proteolysis drives the cell cycle. Science (New York, NY) 274:1652-1659

9. Lukas C, Sørensen CS, Kramer E et al (1999) Accumulation of cyclin B1 requires E2F and cyclin-A-dependent rearrangement of the anaphase-promoting complex. Nature 401:815-818. doi: $10.1038 / 44611$

10. Hsu JY, Reimann JDR, Sørensen CS et al (2002) E2F-dependent accumulation of hEmil regulates $\mathrm{S}$ phase entry by inhibiting APC(Cdh1). Nat Cell Biol 4:358-366. doi:10.1038/ncb785

11. Pines J (2011) Cubism and the cell cycle: the many faces of the APC/C. Nat Rev Mol Cell Biol 12:427-438. doi:10.1038/ nrm3132

12. Chang L, Zhang Z, Yang J et al (2014) Molecular architecture and mechanism of the anaphase-promoting complex. Nature 513:388-393. doi:10.1038/nature 13543

13. Sudakin V, Ganoth D, Dahan A et al (1995) The cyclosome, a large complex containing cyclin-selective ubiquitin ligase activity, targets cyclins for destruction at the end of mitosis. Mol Biol Cell 6:185-197

14. King RW, Peters JM, Tugendreich S et al (1995) A 20S complex containing $\mathrm{CDC} 27$ and $\mathrm{CDC} 16$ catalyzes the mitosis-specific conjugation of ubiquitin to cyclin B. Cell 81:279-288

15. Yamashita YM, Nakaseko Y, Samejima I et al (1996) $20 \mathrm{~S}$ cyclosome complex formation and proteolytic activity inhibited by the cAMP/PKA pathway. Nature 384:276-279. doi:10.1038/ $384276 \mathrm{a} 0$ 
16. Irniger S, Piatti S, Michaelis C, Nasmyth K (1995) Genes involved in sister chromatid separation are needed for B-type cyclin proteolysis in budding yeast. Cell 81:269-278

17. Zachariae W, Shin TH, Galova M et al (1996) Identification of subunits of the anaphase-promoting complex of Saccharomyces cerevisiae. Science (New York, NY) 274:1201-1204

18. Barford D (2015) Understanding the structural basis for controlling chromosome division. Philos Trans A Math Phys Eng Sci 373:20130392. doi:10.1098/rsta.2013.0392

19. Sivakumar S, Gorbsky GJ (2015) Spatiotemporal regulation of the anaphase-promoting complex in mitosis. Nat Rev Mol Cell Biol 16:82-94. doi:10.1038/nrm3934

20. Schreiber A, Stengel F, Zhang Z et al (2011) Structural basis for the subunit assembly of the anaphase-promoting complex. Nature 470:227-232. doi:10.1038/nature09756

21. Herzog F, Primorac I, Dube P et al (2009) Structure of the anaphase-promoting complex/cyclosome interacting with a mitotic checkpoint complex. Science (New York, NY) 323:1477-1481. doi:10.1126/science. 1163300

22. Kimata Y, Baxter JE, Fry AM, Yamano H (2008) A role for the Fizzy/Cdc20 family of proteins in activation of the APC/C distinct from substrate recruitment. Mol Cell 32:576-583. doi:10.1016/j.molcel.2008.09.023

23. Kramer ER, Scheuringer N, Podtelejnikov AV et al (2000) Mitotic regulation of the APC activator proteins CDC20 and CDH1. Mol Biol Cell 11:1555-1569

24. Kotani S, Tanaka H, Yasuda H, Todokoro K (1999) Regulation of APC activity by phosphorylation and regulatory factors. J Cell Biol 146:791-800

25. Visintin R, Craig K, Hwang ES et al (1998) The phosphatase Cdc14 triggers mitotic exit by reversal of Cdk-dependent phosphorylation. Mol Cell 2:709-718

26. D'Amours D, Stegmeier F, Amon A (2004) Cdc14 and condensin control the dissolution of cohesin-independent chromosome linkages at repeated DNA. Cell 117:455-469. doi:10.1038/nrm1441

27. Berdougo E, Nachury MV, Jackson PK, Jallepalli PV (2008) The nucleolar phosphatase Cdc14B is dispensable for chromosome segregation and mitotic exit in human cells. Cell Cycle 7:1184-1190

28. Moshe Y, Boulaire J, Pagano M, Hershko A (2004) Role of Polo-like kinase in the degradation of early mitotic inhibitor 1 , a regulator of the anaphase promoting complex/cyclosome. Proc Natl Acad Sci USA 101:7937-7942. doi:10.1073/pnas. 0402442101

29. Miller JJ, Summers MK, Hansen DV et al (2006) Emil stably binds and inhibits the anaphase-promoting complex/cyclosome as a pseudosubstrate inhibitor. Genes Dev 20:2410-2420. doi:10.1101/gad.1454006

30. Hansen DV, Loktev AV, Ban KH, Jackson PK (2004) Plk1 regulates activation of the anaphase promoting complex by phosphorylating and triggering SCFbetaTrCP-dependent destruction of the APC Inhibitor Emi1. Mol Biol Cell 15:5623-5634. doi:10.1091/mbc.E04-07-0598

31. Di Fiore B, Pines J (2007) Emi1 is needed to couple DNA replication with mitosis but does not regulate activation of the mitotic APC/C. J Cell Biol 177:425-437. doi:10.1083/jcb.200611166

32. De Antoni A, Pearson CG, Cimini D et al (2005) The Mad1/ Mad2 complex as a template for Mad2 activation in the spindle assembly checkpoint. Curr Biol CB 15:214-225. doi:10.1016/j. cub.2005.01.038

33. Sudakin V, Chan GK, Yen TJ (2001) Checkpoint inhibition of the APC/C in HeLa cells is mediated by a complex of BUBR1, BUB3, CDC20, and MAD2. J Cell Biol 154:925-936. doi:10. 1083/jcb.200102093
34. Hardwick KG, Johnston RC, Smith DL, Murray AW (2000) MAD3 encodes a novel component of the spindle checkpoint which interacts with Bub3p, Cdc20p, and Mad2p. J Cell Biol 148:871-882

35. Fraschini R, Beretta A, Sironi L et al (2001) Bub3 interaction with Mad2, Mad3 and Cdc20 is mediated by WD40 repeats and does not require intact kinetochores. EMBO J 20:6648-6659. doi:10.1093/emboj/20.23.6648

36. Rischitor PE, May KM, Hardwick KG (2007) Bub1 is a fission yeast kinetochore scaffold protein, and is sufficient to recruit other spindle checkpoint proteins to ectopic sites on chromosomes. PLoS One 2:e1342. doi:10.1371/journal.pone.0001342

37. Kraft C, Herzog F, Gieffers C et al (2003) Mitotic regulation of the human anaphase-promoting complex by phosphorylation. EMBO J 22:6598-6609. doi:10.1093/emboj/cdg627

38. Shteinberg M, Protopopov Y, Listovsky T et al (1999) Phosphorylation of the cyclosome is required for its stimulation by Fizzy/cdc20. Biochem Biophys Res Commun 260:193-198. doi:10.1006/bbrc.1999.0884

39. Rudner AD, Murray AW (2000) Phosphorylation by Cdc 28 activates the Cdc20-dependent activity of the anaphase-promoting complex. J Cell Biol 149:1377-1390

40. van Vugt MATM, van de Weerdt BCM, Vader G et al (2004) Polo-like kinase- 1 is required for bipolar spindle formation but is dispensable for anaphase promoting complex/Cdc20 activation and initiation of cytokinesis. J Biol Chem 279:36841-36854

41. Lenart P, Petronczki M, Steegmaier M et al (2007) The smallmolecule inhibitor BI 2536 reveals novel insights into mitotic roles of polo-like kinase 1. Curr Biol CB 17:304-315. doi:10. 1016/j.cub.2006.12.046

42. Glotzer M, Murray AW, Kirschner MW (1991) Cyclin is degraded by the ubiquitin pathway. Nature 349:132-138. doi:10. $1038 / 349132 \mathrm{a} 0$

43. Pfleger CM, Lee E, Kirschner MW (2001) Substrate recognition by the Cdc20 and Cdh1 components of the anaphase-promoting complex. Genes Dev 15:2396-2407

44. den Elzen N, Pines J (2001) Cyclin A is destroyed in prometaphase and can delay chromosome alignment and anaphase. J Cell Biol 153:121-136

45. Geley S, Kramer E, Gieffers C et al (2001) Anaphase-promoting complex/cyclosome-dependent proteolysis of human cyclin A starts at the beginning of mitosis and is not subject to the spindle assembly checkpoint. J Cell Biol 153:137-148

46. Hayes MJ, Kimata Y, Wattam SL et al (2006) Early mitotic degradation of Nek2A depends on Cdc20-independent interaction with the APC/C. Nat Cell Biol 8:607-614. doi:10.1038/ ncb 1410

47. Hames RS, Wattam SL, Yamano H et al (2001) APC/C-mediated destruction of the centrosomal kinase Nek2A occurs in early mitosis and depends upon a cyclin A-type D-box. EMBO J 20:7117-7127. doi:10.1093/emboj/20.24.7117

48. Thornton BR, Toczyski DP (2003) Securin and B-cyclin/CDK are the only essential targets of the APC. Nat Cell Biol 5:1090-1094. doi:10.1038/ncb1066

49. Cohen-Fix O, Peters JM, Kirschner MW, Koshland D (1996) Anaphase initiation in Saccharomyces cerevisiae is controlled by the APC-dependent degradation of the anaphase inhibitor Pds1p. Genes Dev 10:3081-3093

50. Michaelis C, Ciosk R, Nasmyth K (1997) Cohesins: chromosomal proteins that prevent premature separation of sister chromatids. Cell 91:35-45

51. Gallant P, Nigg EA (1992) Cyclin B2 undergoes cell cycledependent nuclear translocation and when expressed as a nondestructible mutant, causes mitotic arrest in HeLa cells. J Cell Biol 117:213-224 
52. Murray AW, Solomon MJ, Kirschner MW (1989) The role of cyclin synthesis and degradation in the control of maturation promoting factor activity. Nature 339:280-286. doi:10.1038/ 339280a0

53. Ghiara JB, Richardson HE, Sugimoto K et al (1991) A cyclin B homolog in S. cerevisiae: chronic activation of the Cdc28 protein kinase by cyclin prevents exit from mitosis. Cell 65:163-174

54. Luca FC, Shibuya EK, Dohrmann CE, Ruderman JV (1991) Both cyclin A delta 60 and B delta 97 are stable and arrest cells in M-phase, but only cyclin B delta 97 turns on cyclin destruction. EMBO J 10:4311-4320

55. Schwab M, Lutum AS, Seufert W (1997) Yeast Hct1 is a regulator of Clb2 cyclin proteolysis. Cell 90:683-693

56. Visintin R, Prinz S, Amon A (1997) CDC20 and CDH1: a family of substrate-specific activators of APC-dependent proteolysis. Science (New York, NY) 278:460-463

57. Sikorski RS, Michaud WA, Wootton JC et al (1991) TPR proteins as essential components of the yeast cell cycle. Cold Spring Harb Symp Quant Biol 56:663-673

58. Yu H, Peters JM, King RW et al (1998) Identification of a cullin homology region in a subunit of the anaphase-promoting complex. Science (New York, NY) 279:1219-1222

59. Peters J-M (2006) The anaphase promoting complex/cyclosome: a machine designed to destroy. Nat Rev Mol Cell Biol 7:644-656

60. Zachariae W, Shevchenko A, Andrews PD et al (1998) Mass spectrometric analysis of the anaphase-promoting complex from yeast: identification of a subunit related to cullins. Science (New York, NY) 279:1216-1219

61. Delgado-Esteban M, García-Higuera I, Maestre C et al (2013) APC/C-Cdh1 coordinates neurogenesis and cortical size during development. Nat Commun 4:2879. doi:10.1038/ncomms3879

62. García-Higuera I, Manchado E, Dubus P et al (2008) Genomic stability and tumour suppression by the APC/C cofactor Cdh1. Nat Cell Biol 10:802-811

63. Jackson SP, Bartek J (2009) The DNA-damage response in human biology and disease. Nature 461:1071-1078. doi:10. 1038/nature 08467

64. Elledge SJ (1996) Cell cycle checkpoints: preventing an identity crisis. Science (New York, NY) 274:1664-1672

65. Lamarche BJ, Orazio NI, Weitzman MD (2010) The MRN complex in double-strand break repair and telomere maintenance. FEBS Lett 584:3682-3695. doi:10.1016/j.febslet.2010.07.029

66. Parrilla-Castellar ER, Arlander SJH, Karnitz L (2004) Dial 9-1-1 for DNA damage: the Rad9-Hus1-Rad1 (9-1-1) clamp complex. DNA Repair 3:1009-1014. doi:10.1016/j.dnarep.2004.03.032

67. Matsuoka S, Ballif BA, Smogorzewska A et al (2007) ATM and ATR substrate analysis reveals extensive protein networks responsive to DNA damage. Science (New York, NY) 316:1160-1166. doi:10.1126/science.1140321

68. Matsuoka S, Huang M, Elledge SJ (1998) Linkage of ATM to cell cycle regulation by the Chk2 protein kinase. Science (New York, NY) 282:1893-1897

69. Sanchez Y, Wong C, Thoma RS et al (1997) Conservation of the Chk1 checkpoint pathway in mammals: linkage of DNA damage to Cdk regulation through Cdc25. Science (New York, NY) 277:1497-1501

70. Peng CY, Graves PR, Thoma RS et al (1997) Mitotic and G2 checkpoint control: regulation of 14-3-3 protein binding by phosphorylation of Cdc25C on serine-216. Science (New York, NY) 277:1501-1505

71. McGowan CH, Russell P (1993) Human Weel kinase inhibits cell division by phosphorylating p34cdc2 exclusively on Tyr15. EMBO J 12:75-85
72. Mailand N, Falck J, Lukas C et al (2000) Rapid destruction of human Cdc25A in response to DNA damage. Science (New York, NY) 288:1425-1429

73. Sørensen CS, Syljuåsen RG, Falck J et al (2003) Chk1 regulates the $S$ phase checkpoint by coupling the physiological turnover and ionizing radiation-induced accelerated proteolysis of Cdc25A. Cancer Cell 3:247-258

74. Guo Z, Kumagai A, Wang SX, Dunphy WG (2000) Requirement for Atr in phosphorylation of Chk1 and cell cycle regulation in response to DNA replication blocks and UVdamaged DNA in Xenopus egg extracts. Genes Dev 14:2745-2756. doi:10.1101/gad.842500

75. Liu Q, Guntuku S, Cui XS et al (2000) Chk1 is an essential kinase that is regulated by Atr and required for the G(2)/M DNA damage checkpoint. Genes Dev 14:1448-1459

76. Lukas C, Falck J, Bartkova J et al (2003) Distinct spatiotemporal dynamics of mammalian checkpoint regulators induced by DNA damage. Nat Cell Biol 5:255-260

77. Tibbetts RS, Brumbaugh KM, Williams JM et al (1999) A role for ATR in the DNA damage-induced phosphorylation of p53. Genes Dev 13:152-157

78. Shieh SY, Ahn J, Tamai K et al (2000) The human homologs of checkpoint kinases Chk1 and Cds1 (Chk2) phosphorylate p53 at multiple DNA damage-inducible sites. Genes Dev 14:289-300

79. Banin S, Moyal L, Shieh S et al (1998) Enhanced phosphorylation of p53 by ATM in response to DNA damage. Science (New York, NY) 281:1674-1677

80. Siliciano JD, Canman CE, Taya Y et al (1997) DNA damage induces phosphorylation of the amino terminus of p53. Genes Dev 11:3471-3481

81. Canman CE, Lim DS, Cimprich KA et al (1998) Activation of the ATM kinase by ionizing radiation and phosphorylation of p53. Science (New York, NY) 281:1677-1679

82. Honda R, Tanaka H, Yasuda H (1997) Oncoprotein MDM2 is a ubiquitin ligase E3 for tumor suppressor p53. FEBS Lett 420:25-27

83. Khosravi R, Maya R, Gottlieb T et al (1999) Rapid ATM-dependent phosphorylation of MDM2 precedes p53 accumulation in response to DNA damage. Proc Natl Acad Sci USA 96:14973-14977

84. Maya R, Balass M, Kim ST et al (2001) ATM-dependent phosphorylation of $\mathrm{Mdm} 2$ on serine 395: role in p53 activation by DNA damage. Genes Dev 15:1067-1077. doi:10.1101/gad. 886901

85. Harper JW, Adami GR, Wei N et al (1993) The p21 Cdk-interacting protein Cip1 is a potent inhibitor of G1 cyclindependent kinases. Cell 75:805-816

86. El-Deiry WS, Tokino T, Velculescu VE et al (1993) WAF1, a potential mediator of p53 tumor suppression. Cell 75:817-825

87. Fornace AJ, Alamo I, Hollander MC (1988) DNA damage-inducible transcripts in mammalian cells. Proc Natl Acad Sci USA 85:8800-8804

88. Wang XW, Zhan Q, Coursen JD et al (1999) GADD45 induction of a G2/M cell cycle checkpoint. Proc Natl Acad Sci USA 96:3706-3711

89. Shaltiel IA, Krenning L, Bruinsma W, Medema RH (2015) The same, only different-DNA damage checkpoints and their reversal throughout the cell cycle. J Cell Sci 128:607-620. doi: $10.1242 /$ jcs. 163766

90. van Vugt MATM, Yaffe MB (2010) Cell cycle re-entry mechanisms after DNA damage checkpoints: giving it some gas to shut off the breaks! Cell Cycle 9:2097-2101. doi:10.4161/cc.9. 11.11840

91. Bartkova J, Rezaei N, Liontos M et al (2006) Oncogene-induced senescence is part of the tumorigenesis barrier imposed by DNA 
damage checkpoints. Nature 444:633-637. doi:10.1038/ nature 05268

92. Baus F, Gire V, Fisher D et al (2003) Permanent cell cycle exit in $\mathrm{G} 2$ phase after DNA damage in normal human fibroblasts. EMBO J 22:3992-4002. doi:10.1093/emboj/cdg387

93. Campisi J, d'Adda di Fagagna F (2007) Cellular senescence: when bad things happen to good cells. Nat Rev Mol Cell Biol 8:729-740. doi:10.1038/nrm2233

94. Sudo T, Ota Y, Kotani S et al (2001) Activation of Cdh1-dependent APC is required for G1 cell cycle arrest and DNA damage-induced $\mathrm{G} 2$ checkpoint in vertebrate cells. EMBO J 20:6499-6508

95. Hall MC, Warren EN, Borchers CH (2004) Multi-kinase phosphorylation of the APC/C activator Cdh1 revealed by mass spectrometry. Cell Cycle 3:1278-1284

96. Reimann JD, Freed E, Hsu JY et al (2001) Emi1 is a mitotic regulator that interacts with $\mathrm{Cdc} 20$ and inhibits the anaphase promoting complex. Cell 105:645-655

97. Margottin-Goguet F, Hsu JY, Loktev A et al (2003) Prophase destruction of Emil by the $\mathrm{SCF}$ (betaTrCP/Slimb) ubiquitin ligase activates the anaphase promoting complex to allow progression beyond prometaphase. Dev Cell 4:813-826

98. Wiebusch L, Hagemeier C (2010) p53- and p21-dependent premature APC/C-Cdh1 activation in $\mathrm{G} 2$ is part of the long-term response to genotoxic stress. Oncogene 29:3477-3489

99. Stegmeier F, Visintin R, Amon A (2002) Separase, polo kinase, the kinetochore protein Slk19, and Spo12 function in a network that controls Cdc14 localization during early anaphase. Cell 108:207-220

100. Jaspersen SL, Charles JF, Morgan DO (1999) Inhibitory phosphorylation of the APC regulator Hct1 is controlled by the kinase Cdc28 and the phosphatase Cdc14. Curr Biol CB 9:227-236

101. Bassermann F, Frescas D, Guardavaccaro D et al (2008) The Cdc14B-Cdh1-Plk1 axis controls the G2 DNA-damage-response checkpoint. Cell 134:256-267

102. De Wulf P, Visintin R (2008) Cdc14B and APC/C tackle DNA damage. Cell 134:210-212. doi:10.1016/j.cell.2008.07.004

103. Zhang D, Zaugg K, Mak TW, Elledge SJ (2006) A role for the deubiquitinating enzyme USP28 in control of the DNA-damage response. Cell 126:529-542. doi:10.1016/j.cell.2006.06.039

104. Bassermann F, Pagano M (2010) Dissecting the role of ubiquitylation in the DNA damage response checkpoint in G2. Cell Death Differ 17:78-85. doi:10.1038/cdd.2009.104

105. Badodi S, Baruffaldi F, Ganassi M et al (2015) Phosphorylationdependent degradation of MEF2C contributes to regulate G2/M transition. Cell Cycle 14:1517-1528. doi:10.1080/15384101. 2015.1026519

106. Laoukili J, Álvarez-Fernández M, Stahl M, Medema RH (2008) FoxM1 is degraded at mitotic exit in a Cdh1-dependent manner. Cell Cycle 7:2720-2726

107. Park HJ, Costa RH, Lau LF et al (2008) Anaphase-promoting complex/cyclosome-CDH1-mediated proteolysis of the forkhead box M1 transcription factor is critical for regulated entry into S phase. Mol Cell Biol 28:5162-5171. doi:10.1128/MCB. 00387-08

108. Jeong H-C, Gil N-Y, Lee H-S et al (2015) Timely degradation of Wip1 phosphatase by APC/C activator protein Cdh1 is necessary for normal mitotic progression. $\mathrm{J}$ Cell Biochem 116:1602-1612. doi:10.1002/jcb.25114

109. Lindqvist A, de Bruijn M, Macurek L et al (2009) Wip1 confers G2 checkpoint recovery competence by counteracting p53-dependent transcriptional repression. EMBO J 28:3196-3206. doi:10.1038/emboj.2009.246

110. Macůrek L, Lindqvist A, Voets O et al (2010) Wip1 phosphatase is associated with chromatin and dephosphorylates
gammaH2AX to promote checkpoint inhibition. Oncogene 29:2281-2291. doi:10.1038/onc.2009.501

111. Cha H, Lowe JM, Li H et al (2010) Wip1 directly dephosphorylates gamma-H2AX and attenuates the DNA damage response. Cancer Res 70:4112-4122. doi:10.1158/0008-5472. CAN-09-4244

112. Moon S-H, Lin L, Zhang X et al (2010) Wild-type p53-induced phosphatase 1 dephosphorylates histone variant gamma-H2AX and suppresses DNA double strand break repair. J Biol Chem 285:12935-12947. doi:10.1074/jbc.M109.071696

113. Lieber MR (2010) The mechanism of double-strand DNA break repair by the nonhomologous DNA end-joining pathway. Annu Rev Biochem 79:181-211

114. Wyman C, Ristic D, Kanaar R (2004) Homologous recombination-mediated double-strand break repair. DNA Repair 3:827-833

115. Ciccia A, Elledge SJ (2010) The DNA damage response: making it safe to play with knives. Mol Cell 40:179-204. doi:10. 1016/j.molcel.2010.09.019

116. Trickey M, Grimaldi M, Yamano H (2008) The anaphase-promoting complex/cyclosome controls repair and recombination by ubiquitylating Rhp54 in fission yeast. Mol Cell Biol 28:3905-3916

117. Wang B, Matsuoka S, Ballif BA et al (2007) Abraxas and RAP80 form a BRCA1 protein complex required for the DNA damage response. Science (New York, NY) 316:1194-1198. doi:10.1126/science.1139476

118. Cho HJ, Lee EH, Han SH et al (2012) Degradation of human RAP80 is cell cycle regulated by $\mathrm{Cdc} 20$ and $\mathrm{Cdh} 1$ ubiquitin ligases. Mol Cancer Res 10:615-625. doi:10.1158/1541-7786. MCR-11-0481

119. Lafranchi L, de Boer HR, de Vries EGE et al (2014) APC/ $\mathrm{C}(\mathrm{Cdh} 1)$ controls CtIP stability during the cell cycle and in response to DNA damage. EMBO J 33:2860-2879. doi:10. 15252/embj.201489017

120. Mocciaro A, Berdougo E, Zeng K et al (2010) Vertebrate cells genetically deficient for Cdc14A or Cdc14B retain DNA damage checkpoint proficiency but are impaired in DNA repair. J Cell Biol 189:631-639. doi:10.1083/jcb.200910057

121. Cotto-Rios XM, Jones MJK, Busino L et al (2011) APC/CCdh1dependent proteolysis of USP1 regulates the response to UVmediated DNA damage. J Cell Biol 194:177-186. doi:10.1083/ jcb.201101062

122. Zou L, Elledge SJ (2003) Sensing DNA damage through ATRIP recognition of RPA-ssDNA complexes. Science (New York, NY) 300:1542-1548. doi:10.1126/science.1083430

123. Cimprich KA, Cortez D (2008) ATR: an essential regulator of genome integrity. Nat Rev Mol Cell Biol 9:616-627. doi:10. 1038/nrm2450

124. Wang X, Zou L, Lu T et al (2006) Rad17 phosphorylation is required for claspin recruitment and Chk1 activation in response to replication stress. Mol Cell 23:331-341. doi:10.1016/j. molcel.2006.06.022

125. Bao S, Tibbetts RS, Brumbaugh KM et al (2001) ATR/ATMmediated phosphorylation of human Rad17 is required for genotoxic stress responses. Nature 411:969-974. doi:10.1038/ 35082110

126. Zhang L, Park C-H, Wu J et al (2010) Proteolysis of Rad17 by Cdh1/APC regulates checkpoint termination and recovery from genotoxic stress. EMBO J 29:1726-1737

127. Yamada M, Watanabe K, Mistrik M et al (2013) ATR-Chk1APC/CCdh1-dependent stabilization of Cdc7-ASK (Dbf4) kinase is required for DNA lesion bypass under replication stress. Genes Dev 27:2459-2472. doi:10.1101/gad.224568.113

128. Povlsen LK, Beli P, Wagner SA et al (2012) Systems-wide analysis of ubiquitylation dynamics reveals a key role for PAF15 
ubiquitylation in DNA-damage bypass. Nat Cell Biol 14:1089-1098. doi:10.1038/ncb2579

129. Emanuele MJ, Ciccia A, Elia AEH, Elledge SJ (2011) Proliferating cell nuclear antigen (PCNA)-associated KIAA0101/ PAF15 protein is a cell cycle-regulated anaphase-promoting complex/cyclosome substrate. Proc Natl Acad Sci USA 108:9845-9850. doi:10.1073/pnas.1106136108

130. Williamson A, Banerjee S, Zhu X et al (2011) Regulation of ubiquitin chain initiation to control the timing of substrate degradation. Mol Cell 42:744-757. doi:10.1016/j.molcel.2011.04.022

131. Ostapenko D, Burton JL, Solomon MJ (2012) Identification of anaphase promoting complex substrates in $S$. cerevisiae. PLoS One 7:e45895. doi:10.1371/journal.pone.0045895

132. Eguren M, Porlan E, Manchado E et al (2013) The APC/C cofactor Cdh1 prevents replicative stress and p53-dependent cell death in neural progenitors. Nat Commun 4:2880. doi:10.1038/ ncomms 3880

133. Greil C, Krohs J, Schnerch D et al (2015) The role of APC/ $\mathrm{C}(\mathrm{Cdh} 1)$ in replication stress and origin of genomic instability. Oncogene. doi:10.1038/onc.2015.367

134. Engelbert D, Schnerch D, Baumgarten A, Wäsch R (2008) The ubiquitin ligase $\mathrm{APC}(\mathrm{Cdh} 1)$ is required to maintain genome integrity in primary human cells. Oncogene 27:907-917

135. Song MS, Carracedo A, Salmena L et al (2011) Nuclear PTEN regulates the APC-CDH1 tumor-suppressive complex in a phosphatase-independent manner. Cell 144:187-199. doi:10. 1016/j.cell.2010.12.020
136. Kim H-S, Vassilopoulos A, Wang R-H et al (2011) SIRT2 maintains genome integrity and suppresses tumorigenesis through regulating APC/C activity. Cancer Cell 20:487-499. doi:10.1016/j.ccr.2011.09.004

137. Takahashi A, Imai Y, Yamakoshi K et al (2012) DNA damage signaling triggers degradation of histone methyltransferases through APC/C(Cdh1) in senescent cells. Mol Cell 45:123-131. doi:10.1016/j.molcel.2011.10.018

138. The I, Ruijtenberg S, Bouchet BP et al (2015) Rb and FZR1/ Cdh1 determine CDK4/6-cyclin D requirement in C. elegans and human cancer cells. Nat Commun 6:5906. doi: 10.1038/ ncomms6906

139. de Lange J, Faramarz A, Oostra AB et al (2015) Defective sister chromatid cohesion is synthetically lethal with impaired APC/C function. Nat Commun 6:8399. doi: 10.1038/ncomms9399

140. Sackton KL, Dimova N, Zeng X et al (2014) Synergistic blockade of mitotic exit by two chemical inhibitors of the APC/ C. Nature 514:646-649. doi:10.1038/nature13660

141. Davoli T, Denchi EL, de Lange T (2010) Persistent telomere damage induces bypass of mitosis and tetraploidy. Cell 141:81-93. doi:10.1016/j.cell.2010.01.031

142. Sigl R, Wandke C, Rauch V et al (2009) Loss of the mammalian APC/C activator FZR1 shortens G1 and lengthens S phase but has little effect on exit from mitosis. J Cell Sci 122:4208-4217. doi: $10.1242 /$ jcs. 054197 